\title{
A new hybrid method for selecting the best project manager: TODIM-FSE and Behavioral TOPSIS
}

\author{
Yarly Queiroz de Lima ${ }^{a^{*}}$ and Luiz Flavio Autran Monteiro Gomes ${ }^{b}$
}

${ }^{a}$ Petrobras, Brazil

${ }^{b}$ Ibmec University Center, Brazil

CHRON I CLE

\begin{abstract}
A B S T R A C T
This work aims to present the application of Multi-Criteria Decision-Making methods to the process of recruiting candidates for the position of project manager, considering aspects of the decision maker's preferences in uncertain and risk scenarios. Applied, descriptive and experimental, made up of the combined employment TODIM-FSE methods for multi-criteria classification of available candidates, and the method Behavioral TOPSIS, to choose the ideal project manager. The hybrid application of the Multi-Criteria Decision-Making methods TODIM-FSE, method based on Prospect Theory, and Behavioral TOPSIS, which considers the concept of loss aversion of Economic Behavior, is essentially innovative. When using TODIM-FSE and Behavioral TOPSIS, it was verified the explicit incorporation of the risk profile of the decision maker - aggressive, neutral, or conservative - in the context of aversion or propensity to the risks associated with the management of a project. Through the personal recruiting process from a large Brazilian organization, the possibility of adopting the hybrid model resulting from the combination of the two methods in a real situation was validated. Such validation allowed us to conclude that the candidates' classifications and choices, previously normally accepted, were at odds with the profile and risk propensity of the decision makers.
\end{abstract}

Article history:

Received: June 17, 2021

Received in revised format: July

30, 2021

Accepted: August 19, 2021

Available online:

August 19, 2021

Keywords:

Multi-Criteria Decision Making

TODIM-FSE

Behavioral TOPSIS

Recruitment

Project management

\section{Introduction}

Project management inherently involves high levels of risk because projects, by definition, are being executed for the first time (Olson \& Wu, 2010). Kerzner (2011) highlights the relevance of the role of project management as a strategic or core competency necessary for an organization's growth and survival. Large projects are inserted in a unique and challenging context. As Vargas (2018) reports, the choice of Project Manager is one of the most difficult decisions that the senior management of the organization needs to make. To make the recruitment, classification, and choice process of a Project Manager explicit, that is, to mathematically model part of the intrinsic subjectivity of decision making, the use of MultiCriteria Decision Making (MCDM) methods was adopted. To solve the classification problem, a fuzzy extension of TODIM method, (an acronym in portuguese of Multicriteria Interactive Decision Making) (Gomes \& Lima, 1991; Gomes \& Lima, 1992) the Multicriteria Interactive Decision Making method - Fuzzy Synthetic Evaluation (TODIM-FSE) (Gomes et al., 2014; Passos \& Gomes, 2014) was chose. Gomes, Araya and Carignano (2004) highlight that the TODIM method, methodological and conceptual foundation of TODIM-ESF, has a psychological foundation that explicitly considers the behavior of each decision agent in relation to risk, which is therefore the fundamental reason for choosing to solve the proposed

* Corresponding author.

E-mail address: yarly@petrobras.com.br (Y.Q.de Lima)

(c) 2022 Growing Science Ltd. All rights reserved.

doi: $10.5267 /$ j.jpm.2021.8.001 
problem. Once the classification problem was solved, the ideal project manager was chosen through the application of the behavioral TOPSIS method (Yoon \& Kim, 2017). Behavioral TOPSIS allows for the classification of the risk profile of the decision maker, whether aggressive or conservative, to the context of aversion or propensity to accept risks that involve the management of a project.

\section{Literature review}

\subsection{The TODIM-FSE method}

According to Belton and Stewart (2002), MCDM methods can be classified within two major schools: the American and the French. There are also methods that do not fall into any of the two schools (Pomerol \& Barba-Romero, 2000). Belton and Stewart (2002) categorize the MCDM methods into four problems: choice, classification, ordering and description. The TODIM-FSE fits within the classification problem as well as the ELECTRE TRI and UTADIS methods highlighted by Doumpos and Zopounidis (2002). The TODIM-FSE incorporates, in addition to the Prospect Theory (Kahneman \& Tversky, 1979), the Synthetic Fuzzy Evaluation (Lu et al., 1999; Onkal-Engin et al., 2004). In a seminal article, psychologists Kahneman and Tversky (1979) deal with the way an individual makes decisions in situations that involve risk. The so-called Prospect Theory proposes a hypothetical value function that is concave for gains and convex for losses, and steeper for losses than for gains, as shown in Fig. 1.

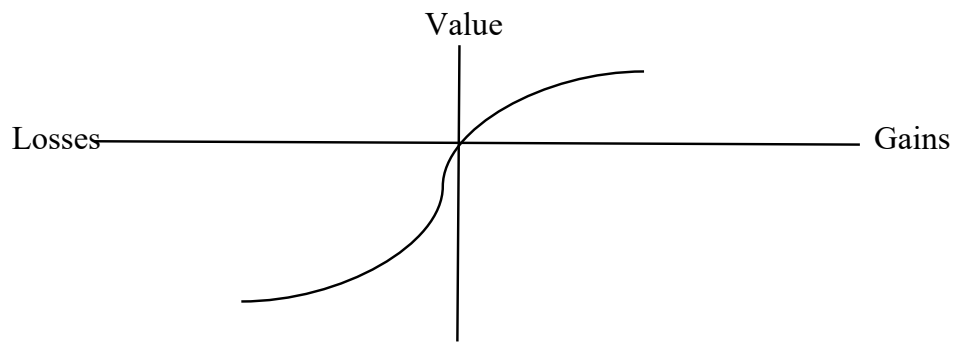

Fig. 1. Hypothetical value function (Gomes \& Lima, 1992)

In other words, people behave in a way that prefers riskier alternatives when what is at stake is the confrontation with a certain loss alternative, but of lesser value. The opposite behavior, of risk aversion, is perceived when the individual is faced with choices between an alternative that allows high gains versus a certain gain of lesser value(Tversky \& Kahneman, 1981). On the other hand, Passos et al. (2014) proposes the fundamental idea of the FSE aggregation procedure as being through a weighted sum of the values associated with each classification category. Thus, TODIM-FSE uses a step-by-step approach, similar to that used by Edwards (1977). The following steps are implemented to solve the decision problem:

Step 1: Definition of decision makers and decision analysts. Decision makers are the people who make value judgments about the decision problem. Decision analysts, in turn, are specialists in decision support processes and methods.

Step 2: Analysis and structuring of the problem. The problem in question is analyzed in detail and, if it is actually a classification of alternatives, the TODIM-FSE can be used.

Step 3: Definition of criteria relevance. The criteria for evaluating the alternatives are selected. These should, preferably, fit the recommendations of Keeney and Raiffa (1993) regarding completeness, operability, minimum size, decomposability and non-redundancy.

Step 4: Definition of categories and contribution functions - Initially, the quantity $k$ of categories must be defined and then the $\mu$ contributions of each criterion $c$ to an alternative, within a given category. Contributions must have values between 0 (minimum contribution) and 1 (maximum contribution).

Table 1

Table of criteria grouped contributions (Passos et al., 2014)

\begin{tabular}{ccccccc}
\hline \multirow{2}{*}{ Criteria } & \multicolumn{5}{c}{ Categories } \\
\cline { 2 - 7 } & $\mathrm{Cat}_{1}$ & $\mathrm{Cat}_{2}$ & $\ldots$ & $\mathrm{Cat}_{\mathrm{I}}$ & $\ldots$ & $\mathrm{Cat}_{\mathrm{K}}$ \\
\hline $\mathrm{c}_{1}$ & $\mu_{11}$ & $\mu_{12}$ & $\ldots$ & $\mu_{1 \mathrm{i}}$ & $\ldots$ & $\mu_{1 \mathrm{k}}$ \\
$\mathrm{c}_{2}$ & $\mu_{21}$ & $\mu_{22}$ & $\ldots$ & $\mu_{2 \mathrm{i}}$ & $\ldots$ & $\mu_{2 \mathrm{k}}$ \\
$\ldots$ & $\ldots$ & $\ldots$ & $\ldots$ & $\ldots$ & $\ldots$ & $\ldots$ \\
$\mathrm{c}_{\mathrm{i}}$ & $\mu_{\mathrm{i} 1}$ & $\mu_{\mathrm{i} 2}$ & $\ldots$ & $\mu_{\mathrm{ji}}$ & $\ldots$ & $\mu_{\mathrm{ik}}$ \\
$\ldots$ & $\ldots$ & $\ldots$ & $\ldots$ & $\ldots$ & $\ldots$ & $\ldots$ \\
$\mathrm{c}_{\mathrm{n}}$ & $\mu_{\mathrm{N} 1}$ & $\mu_{\mathrm{N} 2}$ & $\ldots$ & $\mu_{\mathrm{ni}}$ & $\ldots$ & $\mu_{\mathrm{nk}}$ \\
\hline
\end{tabular}

Quantitative criteria assume continuous values and, therefore, are represented through contribution functions, similar to the construction of fuzzy sets. 
Step 5: Definition of relative importance between criteria. Passos et al. (2014) suggests the adoption of paired pair of criteria, as proposed by Saaty (2008) in the Analytic Hierarchy Process (AHP) method. However, this article used the ranking order centroid (ROC) of Simple Multi-attribute Rating Technique Exploiting Ranks (SMARTER) method (Edwards \& Barron, 1994). The use of ROC is explained in item 3.2.

Step 6: Classification of each alternative in one of the proposed categories $k$. With this, the aggregation function of the TODIM-FSE begins to adopt the data of the $k$ categories defined in step 4 . It is then determined which category the alternative will fall into. From Table 1, we construct $n$ matrices of partial dominance between categories $\phi_{c}\left(\operatorname{Cat}_{i}, \mathrm{Cat}_{j}\right)$, one for each criterion $c$. From these, the final dominance matrix $\delta\left(C a t_{i}, C a t_{j}\right)$ is obtained, calculated using Eq. (1), Eq. (2), Eq. (3) and Eq. (4):

$$
\delta\left(\mathrm{Cat}_{i}, \mathrm{Cat}_{j}\right)=\sum_{c=1}^{n} \phi_{c}\left(\mathrm{Cat}_{i}, \mathrm{Cat}_{j}\right) \quad \forall(i, j)
$$

where

$$
\phi_{c}\left(\text { Cat }_{i}, C_{j}\right)= \begin{cases}\sqrt{\frac{w_{r c}\left(\mu_{i c}-\mu_{j c}\right)}{\sum_{c=1}^{m} w_{r c}}} & \text { if }\left(\mu_{i c}-\mu_{j c}\right)>0 \\ 0 & \text { if }\left(\mu_{i c}-\mu_{j c}\right)=0 \\ \frac{-1}{\theta} \sqrt{\frac{\left(\sum_{c=1}^{m} w_{r c}\right)\left(\mu_{j c} \mu_{i c}\right)}{w_{r c}}} & \text { if }\left(\mu_{i c}-\mu_{j c}\right)<0\end{cases}
$$

$\delta\left(\mathrm{Cat}_{i}, \mathrm{Cat} \mathrm{t}_{j}\right)$ is the measure of dominance of category $i$ over category $j$;

$n$ is the number of criteria;

$c$ is any criterion, for $c=1, \ldots, n$;

$w_{r c}$ is the division of the weight of criterion $\mathrm{c}$ by the weight of the reference criterion;

$\mu_{i c}$ and $\mu_{j c}$ are the contributions of each c criterion to $\mathrm{Cat}_{i}$ and $\mathrm{Cat}_{j}$;

$\theta$ is the loss attenuation factor.

The final classification of the alternative will be obtained by vector $X$, and each $k$ component of the vector represents the final contribution that the alternative has in each chosen category of classification. The $k$ component of the highest value of vector $X$ indicates the category to which the alternative is classified. Each component $\xi_{i}$ is calculated by Eq. (5):

$$
\xi_{i}=\frac{\sum_{j=1}^{k} \delta\left(\text { Cat }_{i}, A_{j}\right)-\min \sum_{j=1}^{k} \delta\left(\text { Cat }_{i}, \text { Cat }_{j}\right)}{\max \sum_{j=1}^{k} \delta\left(\text { Cat }_{i}, C a t_{j}\right)-\min \sum_{j=1}^{k} \delta\left(\text { Cat }_{i}, \text { Cat }_{j}\right)}
$$

Step 7: Validation analysis. In this stage, stress tests and simulations are performed in judgments with imprecise values, to verify the sensitivity of the general classification to variations in them. The consistency between the real problem and the classification obtained in the model can then be verified. If this is not achieved, a re-evaluation of the model's input data becomes necessary. In this way, it may be necessary to establish new weights for the criteria and new contribution functions (Passos et al., 2014).

\subsection{Behavioral TOPSIS}

TODIM-FSE addresses classification issues. Therefore, there remains the need to choose the best option among the alternatives framed in the desired categories. Researchers Yoon and Kim (2017) present a new perspective of TOPSIS (Technique for Order Performance by Similarity to Ideal Solution) by introducing in its formulation behavioral factors of risk aversion or appetite of the decision maker.

First presented by Hwang and Yoon (1981), the TOPSIS method is able to solve problems of choosing the best alternative. Its main concept is in the elaboration of two hypothetical alternatives that will be used as reference points: the ideal positive solution $\left(S^{+}\right)$, formed by the selection of the best evaluations in the criteria in all available alternatives, and the negative ideal solution $\left(S^{-}\right)$formedby the worst evaluations of each criterion in the evaluated alternatives. From these two fictitious 
points, the Euclidean distance is being moved to an alternative $A_{i}$, represented therefore by $\left(A_{i}=D_{i}^{+}, D_{i}^{-}\right), i=1, \ldots, m$ (Yoon \& Hwang, 1995). The TOPSIS value function is written by Yoon and $\operatorname{Kim}(2017)$ as $V=D^{-} / D^{+}$.

TOPSIS orders the alternatives according to their positive ideal solution proximity, thus as far away from the negative ideal solution as possible. For each alternative $A_{i}$ the proximity index $C_{i}=\frac{D_{i}^{-}}{D_{i}^{-}+D_{i}^{+}}, 0<C_{i}<1, i=1,2, \ldots, m$ is determined

Yoon and Kim (2017) introduce the Behavioral TOPSIS with the consideration that the magnitude of the $D_{i}^{-}$is seen as the composition of the gain factor, on the other hand, $D_{i}^{+}$is faced the component of the loss factor. The authors then formulate that the rate of loss aversion is given by:

$\lambda=\frac{\text { deviation for gain }}{\text { deviation for loss }}=\frac{\Delta D^{-}}{\Delta D^{+}}$

Thus, the behavior of choice is contrary to loss when $\lambda>1$, neutral when $\lambda=1$ and prone to loss (or risk appetite) when $\lambda$ $<1$ (YOON and KIM, 2017). Finally, the value function of Behavioral TOPSIS is reformulated, leading to the Eq. (6):

$$
V=D_{i}^{-}-\lambda D_{i}^{+}
$$

Chen (2000) introduces the use of fuzzy techniques in the TOPSIS method. For the author, the fuzzy positive-ideal solution is now described by FPIS $=\left(c_{1}^{+}, c_{2}^{+}, \ldots, c_{n}^{+}\right)$, which $c^{+}$represents the best possible assessment on a given criterion. The opposite equivalent applies to the fuzzy negative-ideal solution $F N I S=\left(c_{1}^{-}, c_{2}^{-}, \ldots, c_{n}^{-}\right)$.

The distances of the alternative $A_{i}$ to FPIS and FNIS are calculated by Eq. (7) and Eq. (8):

$$
\begin{aligned}
& d_{i}^{+}=\sum_{j=1}^{n} d\left(c_{i j}, c_{j}^{+}\right), i=1,2, \ldots, m \\
& d_{i}^{-}=\sum_{j=1}^{n} d\left(c_{i j}, c_{j}^{-}\right), i=1,2, \ldots, m
\end{aligned}
$$

Thus, the fuzzy Euclidean distance is represented by Eq. (9):

$$
d\left(c_{i j}, c_{j}^{+}\right)=\sqrt{\frac{1}{k}\left[\left(c_{11}-c_{1}^{+}\right)^{2}+\cdots+\left(c_{i j}-c_{j}^{+}\right)^{2}+\cdots+\left(c_{n k}-c_{k}^{+}\right)^{2}\right]}
$$

The fuzzy proximity index is described similarly to the original TOPSIS, $C C_{i}=\frac{d_{i}^{-}}{d_{i}^{-}+d_{i}^{+}} 0<C_{i}<1, i=1,2, \ldots, m$.

Finally, we can rewrite Eq. (6) of value function of the Behavioral TOPSIS by adopting the fuzzy vectors computable by Eq. (10):

$$
V=d_{i}^{-}-\lambda d_{i}^{+}
$$

\section{Methodology}

The research methodology applied in this article is of an applied, descriptive and experimental nature. In this work MCDM methods were applied to a real problem of classification and selection of a project manager for a given project. The experimental character of the article is evidenced by the empirical investigation, through which variations of the gain and loss factors of the TODIM-FSE and Behavioral TOPSIS methods are carried out, to observe the adequacy to the decision-maker's risk profiles. Fig. 2 summarizes the frame of reference used for the combined application of the methods.

\subsection{The TODIM-FSE method in classifying project managers}

The evaluation of candidates to assume the management of a project in a large company began with a detailed curriculum survey. Information was sought from experiences in previous projects, specific certifications in project management (Project Management Professional - PMI, PRINCE2 Practitioner, APM Project Management Qualification, Agile Methods, among others), history of projects delivered on time and in budgeted cost, recommendations from sponsors, CEO etc.

Step 1: The decision-making executives were mapped. These are directly linked to the project implementation area, responsible for the organization's investments. There are also analysts who supported the decision support process. 
Step 2: The need to provide decision makers with the categorization of candidates to take on the management of a new project was identified, as well as suggesting the best choice among the classified candidates. Interactions between the human resources analyst and the decision analyst structure the evaluation process in TODIM-FSE.

Step 3: To prepare the evaluation criteria for candidates for the position of project manager, the Individual Competence Baseline (IPMA, 2015) serve as inspiration, the experience in project management of decision and human resources analysts, as well as knowledge of the context of the project under review. The criteria used are summarized in Table 2.

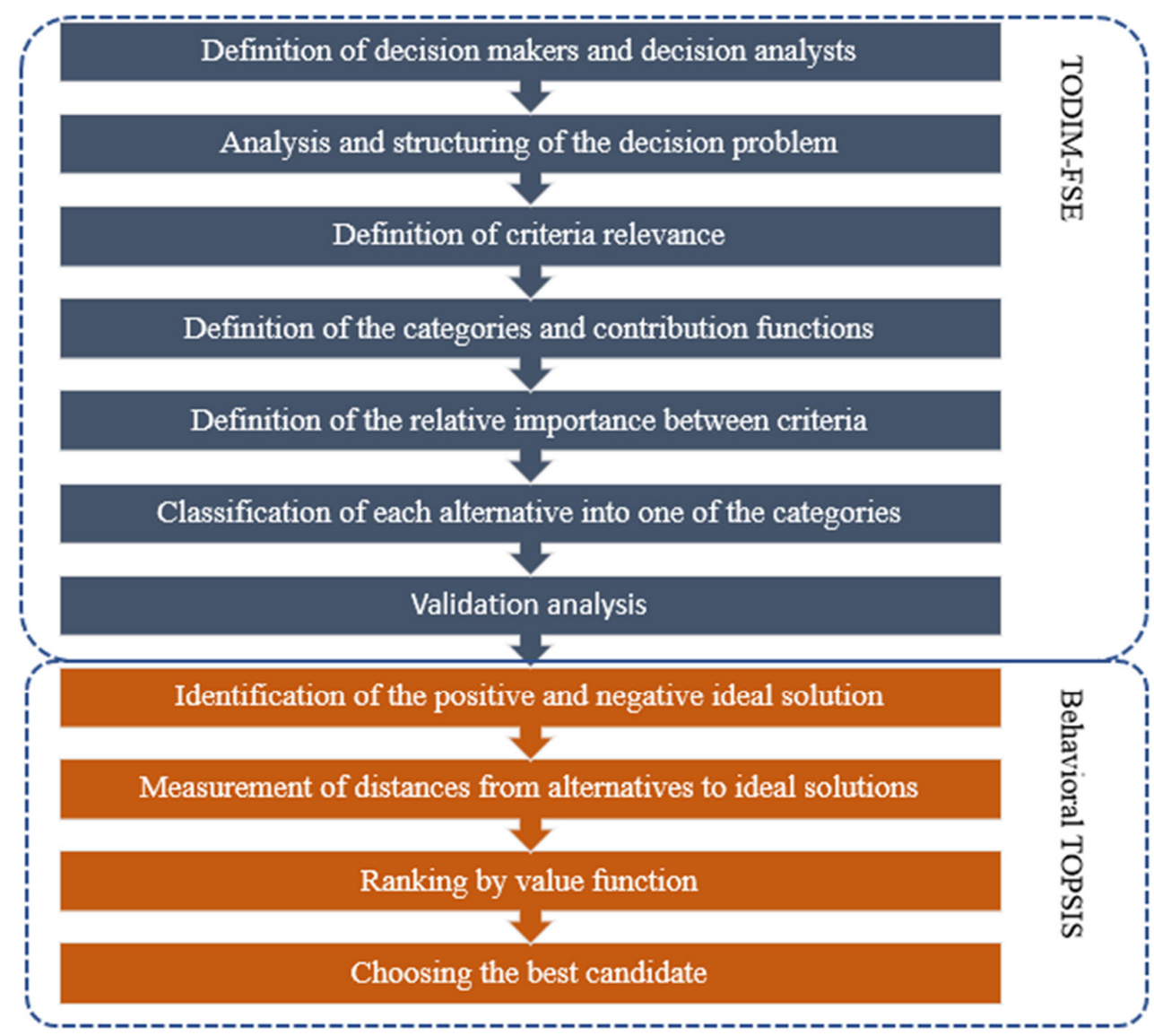

Fig. 2. Framework for the combined application of TODIM-FSE and Behavioral TOPSIS

Table 2

Candidate evaluation criteria

\begin{tabular}{lc}
\hline Criterion & Type \\
\hline Practical Certification in Project Management (PCPM) & Qualitative \\
Certification Method in Project Management (CMPM) & Qualitative \\
Experience in Project Management (EPM) & Quantitative \\
Project delivery on schedule (PDS) & Qualitative \\
Project delivery at budgeted cost (PDBC) & Qualitative \\
Letter of Recommendation (LR) & Qualitative \\
\hline
\end{tabular}

Step 4: For the problem in question, 4 classification categories were defined: Bad (B), Good (G), Very Good (VG) and Excellent (E). In each category, a different contribution was made for each criterion. The criterion of experience in Project Management (EPM) is the only one of the quantitative type, measured in quantity of years. Thus, trapezoidal contribution functions were defined and represented in Fig. 1. 


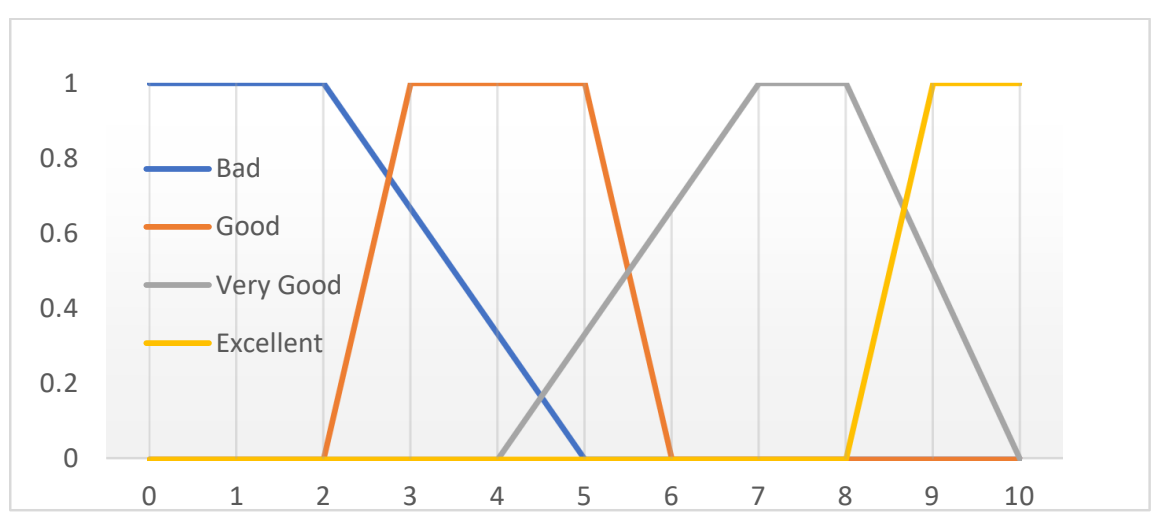

Fig. 1. Function of contribution of the criterion experience in years

As for the other qualitative criteria, Table 3 was adopted for the contribution to the certification criteria (PCPM and CMPM) and the history of projects delivered (PDS and PDBC):

Table 3

Table of contribution to qualitative criteria

\begin{tabular}{|c|c|c|c|c|c|}
\hline Criteria & & tegor & & & \\
\hline PCPM and CMPM & PDS and PDBC & $\mathrm{Bad}$ & Good & Very good & Excellent \\
\hline More than one certification & More than one project delivered & 0 & 0 & 0 & 1 \\
\hline Professional or Practitioner Certification & One project delivered & 0 & 0.5 & 0.7 & 0.1 \\
\hline Foundation certification & Projects delivered with deviations $<10 \%$ & 0.1 & 0.7 & 0.3 & 0 \\
\hline No Certification & No project delivered on schedule and cost & 1 & 0 & 0 & 0 \\
\hline
\end{tabular}

The vector $[0,0,0,1]$ was assumed to be the qualitative criterion Letter of Recommendation (LR) if the candidate had it. On the other hand, the vector $[1,0,0,0]$ was used when the candidate did not show any recommendation.

Step 5: The relative importance of the criteria is given by applying steps 7 and 8 of the SMARTER method (Edwards \& Barron, 1994)

The relative importance among the criteria was defined through the following question: " Imagine an alternative with the worst rating on all criteria. At one point, you will be given the opportunity to achieve the best assessment in only one of the criteria in this alternative. Which criteria would you choose? This questioning is repeated until all the criteria have been ordered and the following dominance is obtained: $P D S>P D B C>E P M>C M P M>P C P M>L R$

The ROC weights were calculated using the proposition of Edwards and Barron (1994) $W_{n}=\left(\frac{1}{n}\right) \sum_{i=n}^{n} \frac{1}{i}$, where $W_{n}$ is the weight of any criterion $c_{n}$, for $c=1, \ldots, n$. Therefore, the weight vector of the criteria: $w=$ $\left[\begin{array}{llllll}0,408 & 0,242 & 0,158 & 0,103 & 0,061 & 0,028\end{array}\right]$

Step 6: Each alternative was evaluated in the proposed categories. In the present work, the suitability of three managers who already occupy a position within the organization under study was evaluated, performing suitability analysis to assume the position of project manager of a new project. Table 4 presents the result of the case study applied to the curriculum of 3 candidates.

Table 4

Results of candidate evaluation

\begin{tabular}{|c|c|c|c|c|c|c|c|c|c|c|c|c|}
\hline \multicolumn{4}{|c|}{ Candidate 1} & \multicolumn{6}{|c|}{ Candidate 2} & \multicolumn{3}{|c|}{ Candidate 3} \\
\hline Criterion & B & $\mathrm{G}$ & VG & $\mathrm{E}$ & B & $\mathrm{G}$ & $\mathrm{VG}$ & $\mathrm{E}$ & B & $\mathrm{G}$ & VG & $\mathrm{E}$ \\
\hline PCPM & 0 & 0 & 0 & 1 & 0 & 0,5 & 0,7 & 0,1 & 0 & 0,5 & 0,7 & 0,1 \\
\hline CMPM & 0,1 & 0,7 & 0,3 & 0 & 1 & 0 & 0 & 0 & 1 & 0 & 0 & 0 \\
\hline EPM & 0 & 0 & 0 & 1 & 0 & 0 & 0,8 & 0,5 & 0 & 1 & 0,3 & 0 \\
\hline PDS & 0 & 0 & 0 & 1 & 0 & 0 & 0 & 1 & 1 & 0 & 0 & 0 \\
\hline PDBC & 0,1 & 0,7 & 0,3 & 0 & 0 & 0,5 & 0,7 & 0,1 & 0 & 0,5 & 0,7 & 0,1 \\
\hline LR & 0 & 0 & 0 & 1 & 1 & 0 & 0 & 0 & 0 & 0 & 0 & 1 \\
\hline
\end{tabular}

Source: own elaboration

The Eqs. (1-4) and Eq. (5) of the TODIM-FSE were applied to obtain the final vector of classification of each alternative. In Table 5, the highest value component $\xi_{i}$ indicates the category selected for the candidate classification. 
Table 5

Global classification of alternatives

\begin{tabular}{ccccc}
\hline$\theta=1$ & Bad & Good & Very good & Excellent \\
\hline Candidate 1 & 0,4 & 0,4 & 0,4 & 0,6 \\
Candidate 2 & 0,1 & 0,3 & 0,4 & 0,7 \\
Candidate 3 & 0,7 & 0,8 & 0,7 & 0,0 \\
$\Theta=5$ & Bad & Good & Very good & Excellent \\
Candidate 1 & 0,6 & 0,6 & 0,6 & 0,8 \\
Candidate 2 & 0,0 & 0,5 & 0,8 & 0,9 \\
Candidate 3 & 0,9 & 1,00 & 0,9 & 0,0 \\
\hline
\end{tabular}

Step 7: Data analysis and validation was carried out together with the decision makers, comparing the candidates classified to the project's risk profile. The adjustments of weights and relevance of the criteria, in addition to the loss attenuation factor $\theta$, proved to be sufficient to assess the robustness of the classification method.

\subsection{The Behavioral TOPSIS method in the choice of classified candidates}

Candidates classified in the Very Good and Excellent categories were considered suitable for the position of new project manager. For a better demonstration of the application of the Behavioral TOPSIS method, candidate 3 remained in the data and results, in addition to the fact that it did not fall into the Bad category. Behavioral TOPSIS completely solved the proposed decision problem, by adding the choice of the best candidate that came closest to the positive ideal alternative and most distanced itself from the negative ideal alternative.

All candidate evaluation criteria were of the benefit type, that is, the longer the experience or the number of projects delivered on time, the better the evaluation. From the values scored by the candidates in Table 4, Table 6 was created for the evaluation of the positive and negative ideal candidate. For each criterion, the best score among the candidates was chosen to compose the evaluation of the ideal positive candidate. The opposite was followed to elaborate the evaluation of the negative-ideal candidate.

Table 6

Candidate evaluation on Behavioral TOPSIS

\begin{tabular}{cccccccccc}
\hline & \multicolumn{3}{c}{ Candidate FPIS } & \multicolumn{4}{c}{ Candidate FNIS } \\
\cline { 2 - 9 } Criterion & B & G & VG & E & B & G & VG & E \\
\hline PCPM & 0 & 0 & 0 & 1 & 0 & 0,5 & 0,7 & 0,1 \\
CMPM & 0,1 & 0,7 & 0,3 & 0 & 1 & 0 & 0 & 0 \\
EPM & 0 & 0 & 0 & 1 & 0 & 1 & 0,3 & 0 \\
PDS & 0 & 0 & 0 & 1 & 1 & 0 & 0 & 0 \\
PDBC & 0 & 0,5 & 0,7 & 0,1 & 0,1 & 0,7 & 0,3 & 0 \\
LR & 0 & 0 & 0 & 1 & 1 & 0 & 0 & 0 \\
\hline
\end{tabular}

Through Eqs. (7-8) and Eq. (9), applied to the evaluation matrices of candidates and ideal candidates, Tables 6 and 4, the Euclidean distance of candidates to ideal alternatives was obtained, see Table 7 .

Table 7

Distance of candidates to ideal alternatives

\begin{tabular}{ccccccccc}
\hline Candidates & PCPM & CMPM & EPM & EPDP & EPCP & LR & $d_{i}^{+}$ \\
\hline Candidate 1 & 0,000 & 0,000 & 0,000 & 0,000 & 0,235 & 0,000 & 0,234 \\
Candidate 2 & 0,622 & 0,589 & 0,472 & 0,000 & 0,000 & 0,707 & 2,390 \\
Candidate 3 & 0,622 & 0,589 & 0,723 & 0,707 & 0,000 & 0,000 & 2,641 \\
\hline & & & & & & & $d_{i}^{-}$ \\
\hline Candidate 1 & 0,622 & 0,589 & 0,723 & 0,707 & 0,000 & 0,707 & 3,349 \\
Candidate 2 & 0,000 & 0,000 & 0,612 & 0,707 & 0,235 & 0,000 & 1,554 \\
Candidate 3 & 0,000 & 0,000 & 0,000 & 0,000 & 0,235 & 0,707 & 0,942 \\
\hline
\end{tabular}


In fuzzy TOPSIS, the option is chosen with the smallest distance from the positive ideal and the greatest distance from the negative ideal. The $C C_{i}$ proximity index measure reveals the ranking in Table 8 .

Table 8

$\underline{\text { Ranking of candidates }}$

\begin{tabular}{ccc}
\hline Candidates & $C C_{i}$ & Ranking \\
\hline Candidate 1 & 0,935 & 1 \\
Candidate 2 & 0.394 & 2 \\
Candidate 3 & 0,263 & 3 \\
\hline
\end{tabular}

The Eq. (10) of the Behavioral TOPSIS introduces the rate of loss aversion $\lambda$ into the value function $V$ of each alternative. The results were obtained for different $\lambda$ values, represented in Table 9.

Table 9

Ranking of the Behavioral TOPSIS Value Function

\begin{tabular}{|c|c|c|c|c|c|c|}
\hline \multirow{2}{*}{ Candidates } & \multicolumn{2}{|c|}{$V_{\text {agressive }}$} & \multicolumn{2}{|c|}{$V_{\text {neutral }}$} & \multicolumn{2}{|c|}{$V_{\text {conservative }}$} \\
\hline & $\lambda=0.5$ & Ranking & $\lambda=1$ & Ranking & $\lambda=1.5$ & Ranking \\
\hline Candidate 1 & 3,23 & 1 & 3,11 & 1 & 2,99 & 1 \\
\hline Candidate 2 & 0,35 & 2 & $-0,83$ & - & -2.02 & - \\
\hline Candidate 3 & $-0,37$ & - & $-1,70$ & - & $-3,02$ & - \\
\hline
\end{tabular}

Source: own elaboration

\section{Analysis of results}

An assessment that considered only the most relevant criterion, PDS, would lead to the choice of Candidate 2, given its track record of success in completing projects within the planned deadline. The application of the TODIM-FSE method in the presented case study reveals that candidates 1 and 2 are suitable to occupy the position of Project Manager in a new project of the organization under study, according to Table 5.

Different values of the loss attenuation factor $\theta$ modeled the different behaviors of the decision maker regarding the risk of losses, as they affect the negative quadrant of the value function of the Prospect Theory, Figure 1 . The greater is $\theta$, the less sensitive to losses is the decision maker, suited to an aggressive and risk-prone profile. Sensitivity analyzes performed on the loss attenuation factor $\theta$ reinforced the robustness of the categorization achieved with TODIM-FSE, according to Table 5 . The selection of the best candidate among the classifieds took place through Behavioral TOPSIS. The ranking in Table 8 positioned Candidate 1 as the ideal alternative among the available options.

By incorporating the loss aversion rate $\lambda$, it was once again possible to adapt the decision maker's choice to the project's risk profile. Furthermore, it made possible a further sensitivity analysis by exerting an additional stress test on the utility value function of each alternative. Candidate 1 was the preferred option in the three risk perspectives presented in Table 9. Only in a context of aggressive risk acceptance, that is, of a greater appetite for uncertain situations, Candidate 2's utility value function was viable; however, it remained an ideal second choice. Candidate 3 , who was intentionally maintained in the Behavioral TOPSIS application, reinforced his inadequacy as the project manager of the new project in any evaluated context.

All criteria adopted in the classification of project manager candidates were of the benefit type. The evaluation did not consider cost-type criteria, such as, for example, salary intention, given the permanence of candidates in the staff of the organization under study

\section{Conclusion}

The TODIM-FSE and Behavioral TOPSIS methods showed excellent response to the classification and selection, respectively, of candidates to occupy the position of Project Manager. Prior to the joint application of MCDM methods, there was an understanding that any one of the three candidates would be able to fill the position on the new project.

The relative mathematical simplicity of the applied methods demonstrated viability in their use as a staff selection and recruitment tool, especially in environments that involve decision-making under uncertainty and risks.

Both TODIM-FSE and Behavioral TOPSIS have mathematical parameters that allow the decision maker to make the necessary adjustments to match the conjectural characteristics of appetite or risk aversion in the decision-making process.

The project in which the study was applied has the implementation deadline as its driver, that is, the success factor is measured by its completion up to a milestone, even if for this it is necessary to invest a greater number of financial resources. This is the main reason why the PDS criterion is the most dominant. In a cost-driven project, the PDBC criteria will certainly be ahead of the others, as well as in a project with innovative and disruptive characteristics, the certification criteria may prove to be more relevant. 
Mainly due to its fuzzy characteristic, future applications of TODIM-FSE in the proposed problem may incorporate behavioral assessment criteria, such as the application of interviews and/or daily simulations, within the context of recruitment, that assess quality and candidate response time to typical project management issues.

\section{References}

Belton, V., \& Stewart, T. J. (2002). Multiple Criteria Decision Analysis. In K. A. Publishers (Ed.), Multiple Criteria Decision Analysis. Springer US. https://doi.org/10.1007/978-1-4615-1495-4

Chen, C. T. (2000). Extensions of the TOPSIS for group decision-making under fuzzy environment. Fuzzy Sets and Systems, 114(1), 1-9. https://doi.org/10.1016/S0165-0114(97)00377-1

Doumpos, M., \& Zopounidis, C. (2002). Multicriteria decision aid classification method. Kluwer Academic Publishers.

Edwards, W. (1977). How to Use Multiattribute Utility Measurement for Social Decision making. IEEE Transactions on Systems, Man and Cybernetics, 7(5), 326-340. https://doi.org/10.1109/TSMC.1977.4309720

Edwards, W., \& Barron, F. H. (1994). SMARTS and SMARTER: Improved Simple Methods for Multiattribute Utility Measurement. In A Science of Decision Making (pp. 306-325). https://doi.org/10.1093/acprof:oso/9780195322989.003.0031

Gomes, L. F. A. M., \& Lima, M. M. P. P. (1991). Todim: Basic and application to multicriteria ranking of projects with environmental impacts. Foundations of Computing and Decision Sciences, 16(4), 113-127.

Gomes, L. F. A. M., Araujo, R. M., \& Machado, M. A. S. (2014). Retail location analysis with TODIM-FSE. Tecnologia \& Cultura, 24, 45-50. https://doi.org/10.1017/CBO9781107415324.004

Gomes, L. F. A. M., Araya, M. C. G., \& Carignano, C. (2004). Tomada de decisões em cenários complexos. Thomson Learning.

Gomes, L. F. A. M., \& Lima, M. M. P. P. (1992). From modelling individual preferences to multicriteria ranking of discrete alternatives: A look of prospect theory and additive difference model. Foundation of Computing and Decision Sciences, 17(3), 171-184.

Gomes, L. F. A. M., Rangel, L. A. D., \& Maranhão, F. J. C. (2009). Multicriteria analysis of natural gas destination in Brazil: An application of the TODIM method. Mathematical and Computer Modelling, 50(1-2), 92-100. https://doi.org/10.1016/j.mcm.2009.02.013

Hwang, C.-L., \& Yoon, K. (1981). Multiple Attribute Decision Making (Vol. 186). Springer Berlin Heidelberg. https://doi.org/10.1007/978-3-642-48318-9

IPMA. (2015). IPMA Individual Competence Baseline (ICB), Version 4.0. IPMA. https://www.ipma.world

Kahneman, B. Y. D., \& Tversky, A. (1979). Prospect Theory: An Analysis of Decision Under Risk. Econometrica, 47(2), $263-291$.

Keeney, R. L., \& Raiffa, H. (1993). Decisions with Multiple Objectives. In IEEE Transactions on Systems, Man and Cybernetics. Cambridge University Press. https://doi.org/10.1017/CBO9781139174084

Kerzner, H. (2011). PROJECT MANAGEMENT METRICS, KPIs, AND DASHBOARDS. John Wiley \& Sons.

Lu, R. S., Lo, S. L., \& Hu, J. Y. (1999). Analysis of reservoir water quality using fuzzy synthetic evaluation. Stochastic Environmental Research and Risk Assessment, 13(5), 327-336. https://doi.org/10.1007/s004770050054

Olson, D. L., \& Wu, D. (2010). Enterprise Risk Management Models. Springer. https://doi.org/10.1007/978-3-642-114748

Onkal-Engin, G., Demir, I., \& Hiz, H. (2004). Assessment of urban air quality in Istanbul using fuzzy synthetic evaluation. Atmospheric Environment, 38(23), 3809-3815. https://doi.org/10.1016/j.atmosenv.2004.03.058

Passos, A. C., \& Gomes, L. F. A. M. (2014). Todim-Fse: A Multicriteria Classification Method Based On Prospect Theory. Multiple Criteria Decision Making, 9(9), 123-139.

Passos, A. C., Teixeira, M. G., Garcia, K. C., Cardoso, A. M., \& Gomes, L. F. A. M. (2014). Using the TODIM-FSE method as a decision-making support methodology for oil spill response. Computers and Operations Research, 42, 40-48. https://doi.org/10.1016/j.cor.2013.04.010

Pomerol, J.-C., \& Barba-Romero, S. (2000). Multicriterion Decision in Management. Springer US. https://doi.org/10.1007/978-1-4615-4459-3

Saaty, T. L. (2008). Decision making with the analytic hierarchy process. International Journal of Services Sciences, 1(1), 83-98. https://doi.org/10.1016/0305-0483(87)90016-8

Tversky, A., \& Kahneman, D. (1981). The Framing of Decisions and the Psychology of Choice. American Association for the Advancement of Science, 211(4481), 453-458.

VARGAS, R. V. (2018). Gerenciamento de Projetos. In Brasport (Ed.), Brasport (9th ed.)

Yoon, K., \& Hwang, C.-L. (1995). Multiple Attribute Decision Making. SAGE Publications, Inc. https://doi.org/10.4135/9781412985161

Yoon, K. P., \& Kim, W. K. (2017). The behavioral TOPSIS. Expert Systems with Applications, 89, $266-272$. https://doi.org/10.1016/j.eswa.2017.07.045 
(c) (1)
(C) 2022 by the authors; licensee Growing Science, Canada. This is an open access article distributed under the terms and conditions of the Creative Commons Attribution (CC-BY) license (http://creativecommons.org/licenses/by/4.0/). 